\title{
Covid e couvade: crenças agnotológicas sobre a covid-19 à luz da epidemiologia de
}

\section{ideias}

\author{
Covid and Couvade: Agnotological Beliefs about covid-19 in the Light of the Epidemiology of Ideas \\ Covid y couvade: creencias agnotológicas sobre covid-19 a la luz de la epidemiologia de las ideas
}

Recebido: 04/01/2022 | Revisado: 09/01/2022 | Aceito: 18/01/2022 | Publicado: 19/01/2022

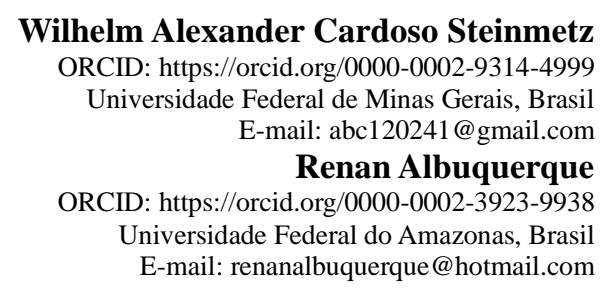

\begin{abstract}
Resumo
Crenças antifáticas e anticientíficas sobre a pandemia da covid-19 se disseminaram amplamente no Brasil em forma de uma epidemia de ideias no sentido de Dan Sperber. Muitas dessas crenças foram propagadas ou encontraram apoio importante no discurso do Presidente da República. Desse modo, analisamos os sentidos manifestos e latentes de 200 declarações do Presidente que foram consideradas falsas ou distorcidas por veículos de fact checking e analisamos a propagação das crenças subjacentes na sociedade à luz das considerações de Sperber. Em particular, traçamos um paralelo entre duas crenças anti-científicas: a crença na utilidade da prática da couvade (amplamente difundida em civilizações de origem pré-colombiana) e a crença na eficácia do "kit covid" na prevenção e no tratamento da covid19 , que pode ser classificada como agnotológica, dada a ampla difusão do conhecimento científico na nossa sociedade moderna. Finalmente, tecemos algumas considerações sobre o potencial da continuada propagação ou da erosão cognitiva de tais crenças agnotológicas.
\end{abstract}

Palavras-chave: Covid-19; Epidemia de ideias; Fake news; Couvade.

\begin{abstract}
Anti-factual and anti-scientific beliefs about the covid-19 pandemic have spread widely in Brazil in the form of an epidemic of ideas in the sense of Dan Sperber. Many of these beliefs were propagated or endorsed in the President of the Republic's speech. In this sense, we analyze the manifest and latent meanings of 200 statements by the President that were considered false or distorted by fact checking vehicles and analyze the propagation of the underlying beliefs in society in the light of Sperber's considerations. In particular, we draw a parallel between two anti-scientific beliefs: the belief in the usefulness of the couvade (widespread in civilizations of pre-Columbian origin) and the belief in the effectiveness of the "covid kit" (a combination of medical drugs that have scientifically shown to be ineffective) in the prevention and treatment of covid-19, which can be classified as agnotological, given the wide diffusion of scientific knowledge in our modern society. Finally, we make some considerations about the potential for the continued propagation or cognitive erosion of such agnotological beliefs.
\end{abstract}

Keywords: Covid-19; Epidemic of ideas; Fake news; Couvade.

\section{Resumen}

Las creencias contra los hechos y no científicas sobre la pandemia del covid-19 se han extendido ampliamente en Brasil en forma de una epidemia de ideas en el sentido de Dan Sperber. Muchas de estas creencias se propagaron o encontraron un apoyo importante en el discurso del Presidente de la República. De esta manera, analizamos los significados manifiestos y latentes de 200 declaraciones del Presidente que fueron consideradas falsas o distorsionadas por vehículos de verificación de hechos y analizamos la propagación de las creencias subyacentes en la sociedad a la luz de las consideraciones de Sperber. En particular, trazamos un paralelo entre dos creencias anticientíficas: la creencia en la utilidad de la práctica de la couvade (muy generalizada en civilizaciones de origen precolombino) y la creencia en la eficacia del "kit covid" para prevenir y tratar la covid-19, que se puede catalogar como agnotológica, dada la amplia difusión del conocimiento científico en nuestra sociedad moderna. Finalmente, hacemos algunas consideraciones sobre el potencial de propagación continua o erosión cognitiva de tales creencias agnotológicas.

Palabras clave: Covid-19; Epidemia de ideas; Fake news; Couvade. 


\section{Introdução}

Na pandemia de covid-19, observa-se, no Brasil e no mundo, a propagação de crenças antifáticas e anticientíficas. Elas são baseadas em informações falsas, contrainformações, rumores ou boatos que se disseminam na forma de uma “epidemia de ideias" sobre a covid-19 em paralelo à própria epidemia biológica. O conceito de epidemia de ideias não é novo. Aparece em trabalhos de Gabriel Tarde (1890, p. 266). Mais recentemente Dan Sperber desenvolveu a proposta com detalhes em La contagion des idées (Sperber, 1996). O propósito do presente trabalho foi analisar conjuntos de crenças agnotológicas sobre a covid-19 à luz das reflexões de Sperber.

Para Sperber, crenças se propagam de forma análoga a uma epidemia biológica na sociedade, por meio de cadeias causais de representações mentais e públicas, as quais se coadunam a representações sociais (Moscovici, 2003). A propagação de crenças pode ocorrer lentamente por meio de gerações, assemelhando-se a uma endemia de transmissão vertical, ou em um espaço de tempo de alguns meses ou poucos anos, como uma moda, por exemplo, sendo comparável então a uma epidemia. Observa-se que certas crenças se propagam com mais facilidade que outras. Surge, então, a pergunta norteadora do trabalho, do porquê disso.

Muitas das crenças agnotológicas relativas à covid-19 de fato se propagaram com muita facilidade nos últimos meses e com efeitos deletérios (Barberia \& Gómez, 2020; Ferrante et al., 2020; Satie, 2021). Analisamos como essa propagação ocorreu devido a atributos intrínsecos às próprias crenças (em particular, um certo simplismo) e devido a fatores ecológicos (discurso do Presidente da República e mecanismos eficientes de disseminação de fake news via redes sociais). Portanto, situamos a investigação no caminho das seguintes questões: i) que características têm as crenças agnotológicas sobre a covid-19? e ii) qual a sua maneira de propagação, dada a grande prevalência dentre a população?

\section{Enfoque Teórico}

Nos tempos presentes, inúmeras crenças sobre a pandemia da covid-19 se contrapõem a informações oficiais de governos, literatura científica e posições da OMS e de sociedades médicas em diferentes países, e dessa forma podem ser classificadas como anticientíficas ou negacionistas. Essas crenças relacionam-se, por exemplo, à eficácia de supostos tratamentos precoces (à base do chamado "kit covid" ou de hidroxicloroquina), certa imunidade natural (graças uma estatura atlética, por exemplo) e à suposta capacidade de vacinas contra o vírus de alterar o DNA humano (SBIM, 2021).

Visto que são crenças propagadas em uma sociedade em que o conhecimento científico é extremamente acessível e implicitamente, e tacitamente, reconhecido como parte integral de nossas atividades do dia a dia, classificamos essas crenças como agnotológicas. Crenças agnotológicas, por sua vez, são frequentemente baseadas em fake news, a saber, informações falsas ou distorcidas, contrainformações, rumores e boatos, criados propositalmente (Greifender et al., 2021; Zattar, 2017), que, por sua parte, possuem uma tendência de se propagar de forma acelerada e com muita facilidade na sociedade (Vosoughi et al., 2018).

No estudo, focamos em crenças que se baseiam em ou são sustentadas por afirmações inverídicas do Presidente da República. Como veremos, grande parte de crenças agnotológicas com forte prevalência possui origem ou foi impulsionada por falas do chefe do Executivo. Partindo do pressuposto que indivíduos agem em função de suas crenças, é fácil enxergar como uma propagação eficiente de crenças agnotológicas pode ter consequências deletérias não só para envolvidos, mas para a sociedade como um todo nessa pandemia, o que, aliás, está amplamente documentado (Barrucho, 2021; Albuquerque et al., 2020).

De fato, no Estado do Amazonas, cuja capital Manaus é uma das mais afetadas no mundo pelo SARS-CoV-2 (Iamarino, 2021), pesquisas indicam que crenças agnotológicas estão amplamente difundidas e seguem padrões de demais capitais brasileiras (Souza Júnior et al., 2020). 
No livro Contagion des idées, Sperber (1996) estuda a cultura de uma perspectiva epidemiológica e aponta que mentes humanas, e por extensão sociedades humanas, estão habitadas por um grande número de ideias, com algumas delas possuindo maior prevalência e se propagando mais ante outras. Essas ideias podem ser crenças religiosas, técnico-científicas, rituais, histórias ou narrativas, em amplos aspectos. As crenças com maior prevalência se tornam "culturais".

Daí que, a partir da perspectiva epidemiológica, Sperber (1996) se questiona porque certas ideias são mais "contagiosas" que outras. O seu conceito de epidemia de ideias, assim, tem características de cunho antropológico, comunicacional e cognitivo (Sperber, 1986/1995). O antropólogo teoriza que ideias se propagam em sociedades via complexas cadeias causais de representações sociais, consistindo alternadamente entre representações mentais (como crenças, intenções e preferências) e públicas (englobando sinais, enunciados, textos e imagens). Por exemplo, uma receita de cozinha pode ser contada por uma mãe a uma filha (o ato de narrar sendo uma representação pública), e esta por sua vez forma uma "imagem" mental da receita ao escutar a mãe falar, isto é, uma representação mental. Se a filha conta por sua vez a receita para uma terceira pessoa, ela produz novamente uma representação pública, que pode aliás ser levemente diferente daquela ouvida da mãe. Dessa maneira, a propagação de uma ideia não ocorre por simples replicação, mas pode sofrer mudanças ou mutações no seu espalhamento, de forma análoga a um vírus.

Desta feita, apesar de certa replicação ocorrer pelo compartilhamento de fake news mediante redes sociais e pelo fato de muitas fake news se propagarem pelo suporte escrito, vemos que a análise de crenças via dinâmica da propagação por cadeias de representações, alternadamente mentais e públicas, é aplicável à atual disseminação de crenças agnotológicas sobre a covid-19. A partir desse ponto de vista, investigamos atributos e circunstâncias as quais fazem com que certas crenças se propaguem mais facilmente em relação a outras, sejam esses fatores intrínsecos ou ecológicos. No trabalho, propomos reflexão sobre a propagação de crenças agnotológicas sobre a pandemia da covid-19, à luz da análise de Sperber.).

\section{Metodologia}

\subsection{Contexto do estudo}

Seguidores e apoiadores políticos do Presidente do Brasil têm sido investigados por supostamente criarem e distribuírem fake news em grande quantidade (Teixeira, 2021). Em particular, um grupo de influenciadores digitais ultraconservadores de viés pró-governo, teria usado redes sociais para desacreditar a pandemia (Schelp, 2021). De fato, um estudo mostra como a crença de que a hidroxicloroquina seja eficaz como tratamento ou cure para covid-19 se propagou de forma muito mais ampla no twitter entre março e julho 2020 do que informações científicas (Recuero et al., 2020).

Ademais, entre 14 de janeiro de 2020 e 14 de janeiro de 2021, o próprio Presidente da República deu 975 declarações de teor falso ou distorcido sobre a covid-19, segundo a organização de fact-checking journalism brasileira "Aos Fatos" (Aos Fatos, 2021). Fact-checking journalism, segundo o painel Communications Oxford Research Encyclopedias (Graves \& Amazeen, 2019), é um trabalho que conglomerados de comunicação/jornalismo realizam, em nível nacional e mundial, a partir de robôs, para uso de dados em larga escala, no intuito de acessar e avaliar dados, atestando a veracidade ou a falsidade de informações.

Há evidências de que declarações do Presidente da República sobre fraudes em eleições coincidiram com picos de compartilhamento de fake news no facebook e no youtube (Ruediger \& Grassi, 2020, p. 18) e que o seu discurso agnotológico referente à pandemia da covid-19 influiu significativamente no comportamento das pessoas no Brasil (Ajzenman et al., 2020). No Amazonas, em consonância a isso, onde o atual chefe do Executivo teve $75 \%$ dos votos de toda a população estadual nas eleições de 2018, a situação de desinformação ante o espalhamento da doença teve implicações na população em geral e entre

${ }^{1} \mathrm{~A}$ base afirma agregar declarações de Bolsonaro feitas a partir do dia de sua posse como presidente. 
médicos do Estado (Satie, 2020; AMB, 2021). A Associação Médica Brasileira revelou que até fevereiro de 2021 a porcentagem de 34,7\% dos profissionais do Amazonas de medicina considerava o uso de cloroquina no tratamento da covid-19 e $41 \%$ de ivermectina. Outros 2,5\% disseram não acreditar nas vacinas (AMB, 2021). O próprio Conselho Federal de Medicina não se posicionou contra a prescrição de cloroquina para tratamento ou prevenção de covid-19 até igual data (Estadão, 2021).

Portanto, o Presidente da República e seus assessores, além de profissionais e conselhos de medicina, podem ser considerados agentes propagadores ou avalizadores de fake news, conforme definição acima. Por conta disso, no que se refere à proposta de estratégia de análise deste artigo, fizemos recorte amostral para narrativas do chefe do Executivo brasileiro e verificamos a dinâmica de reforço em processos de desinformação e contrainformação, além de rumores e boatos.

A hipótese em função do problema é que a narrativa repetida cotidianamente, em sistemática de verdade, pela pessoa mais influente do Executivo federal, e retransmitida por seus apoiadores (muitas vezes ipsis litteris), tem função cumulativa porque se potencializa no comportamento e fixa na mente, sendo sintomatizada em ações do cotidiano, ações públicas, gerando efeitos de pretensa credibilidade na medida em que não é rechaçada ou desacreditada com base em argumentos científicos ou tais contestações não conseguem suplantar narrativas agnotólogicas.

Nesse sentido, já foi mostrado que notícias falsas se propagam com mais facilidade (Vosoughi et al., 2018) ao ponto em que narrativas agnotológicas, inverídicas, frequentemente realizadas por autoridade de grande poder e influência social, tendem a ganhar ares de credibilidade pelo potencial da narrativa investida a partir do próprio cargo ocupado pela pessoa (Cesarino, 2019) e que suas falas possuem influência no comportamento da população (Ajzenman, Cavalcanti \& da Mata, 2020).

\subsection{Amostra}

A amostra foi por conveniência, segundo significância e força das declarações do Presidente Jair Bolsonaro, que ocupa o cargo mais importante do país. Trabalhamos com um recorte de 200 falas publicado em 07/01/2021, no dia em que o país chegou ao patamar de 200.000 mortes por covid-19 (Ribeiro, 2021)2. Essas falas foram classificadas como "falsas ou distorcidas" pelo sistema de verificação do site Aos Fatos, com atualização até 14/01/2021 (Aos Fatos, 2021) e foram todas feitas publicamente pelo Presidente em coletivas de imprensa. O nível de verossimilhança analisado foi pautado no próprio significante de controvérsia encontrado nas falas, comparando-se ao que a Organização Pan-Americana da Saúde (2020), orientada pela Organização Mundial da Saúde, destaca como boas práticas de enfrentamento ao SARS-CoV-2.

\subsection{Procedimento de coleta}

A publicação desse recorte de falas do Presidente da República ocorreu concomitantemente a uma incomum cadeia de eventos que durou cerca de 20 dias e teve grande repercussão no cenário midiático e político. Em poucos dias, o material conheceu inesperada reprodutibilidade e tornou-se viral entre coletivos, redes cidadãs de solidariedade, grupos de apoio a sequelados da covid-19 e profissionais de saúde, além de associações não federadas de professores e assistentes sociais.

Em 13 de janeiro, a organização não governamental Human Rights Watch (HRW) divulgou relatório internacional e dedicou capítulo inteiro ao Presidente Bolsonaro, acusando-o por suas narrativas agnotológicas de "sabotar (sic)" esforços da sociedade brasileira em mitigar o espalhamento do SARS-CoV-2 (Preite Sobrinho, 2021). Com isso, as 200 frases voltaram à baila porque pela primeira vez na história recente da HRW um chefe do Executivo da América Latina era tratado nos termos definidos pela ONG como "sabotador" em sua comunicação com a sociedade.

\footnotetext{
${ }^{2}$ Duas das 200 frases estavam repetidas no original e foram retiradas da análise de inferência, entrando somente no quantitativo numérico. Elas foram classificadas como "não se aplica" (cf. autores).
} 
Depois disso, em 21 de janeiro, o chefe do Executivo era mais uma vez duramente questionado por comunicações em uma das mais respeitadas revistas científicas do mundo, a The Lancet (Hallal, 2021), sete meses depois do mesmo periódico ter criticado de forma contundente a gestão política e a mitigação da pandemia, em maio de 2020, também por depoimentos públicos (The Lancet [Editorial], 2020). A crítica repercutiu e chamou atenção da sociedade e dos autores deste artigo.

Por fim, em 28 de janeiro, o think tank australiano Lowy Institute classificou o Brasil como o pior país do mundo no combate à pandemia da covid-19 entre 98 nações analisadas (Lowy Institute, 2021), representando provavelmente a pior avaliação em termos de saúde pública para o país desde a histórica redemocratização, em 1988, quando foi redigida a Constituição Nacional e acabou a ditadura militar.

Assim, considerando a conjuntura de fatos e em razão do bojo de fortes eventos negativos, todos relacionados à comunicação disfuncional e disruptiva do Presidente, realizamos a escolha de analisar as 200 narrativas, seguindo essa linha do tempo de controvérsias. Elas foram avaliadas qualitativamente, a partir de análise manual de Bardin (2006) e apoio na sistemática de Erk $(2009,2010)$.

\subsection{Procedimento de análise}

Foram avaliadas as 200 narrativas conjunturais segundo frequência de emersão lexical e contabilizadas por tendência semântica e localização significativa de suas partes nas Unidades de Contexto Elementar (UCEs) (Bardin, 2006). Mediante a visibilidade de ocorrências ou co-ocorrências comunicacionais, foram distribuídas classificações por categorias a posteriori, com aporte de leituras de viés flutuante e inferencial.

Cada uma das 200 declarações contém em média 3,8 conjuntos de textualidades ou partes de textualidades significativas, definidos e registrados para verificação a partir de três critérios, literalidade, representatividade e desdobramento interpretativo (Vala, 2003). As declarações foram quantificadas mediante sinais gramaticais comumente usados, a saber: ponto, vírgula dentro da sentença; sentido da oração ou duplo-sentido.

Foram determinadas 760 UCEs de literalidade, representatividade e desdobramento interpretativo para as 200 orações. Incluímos no volume dúbios sentidos, contabilizados como falas co-ocorrentes do Presidente a partir de marcações de sinais gramaticais para teores de expressão facial ou gesticulação dentro da narrativa, a exemplo de pô! Ou p*rra (sic), muito recorrentes. O material transcrito é todo direta e indiretamente relacionado à covid-19, com registros iniciais de 26 de janeiro de 2020 e finais em 5 de janeiro de 2021.

Ao número de UCEs de veiculação pública (760), originadas pelo agente político em análise (chefe do Executivo), somam-se i) retransmissões do emissor/mídia, ii) do receptor/público e iii) compartilhamento em redes sociais. O volume, assim, teve de ser quadruplicado por causa do efeito spread que qualquer informação ganha em razão da alta replicabilidade das falas do presidente, principalmente no território brasileiro, o que nos leva a 3.040 sentidos vinculados às declarações.

Tomamos como amplificador dos rebatimentos (a saber, compartilhamentos) o fato de que, em situações referentes a informações falsas ou contraditórias, por grau de novidade e emoções conjunturais, o limiar de pessoas atingidas se eleva em mais de 1.500, em uma velocidade seis vezes mais rápida que o comum, quando dados verdadeiros são distribuídos (Vosoughi et al., 2018).

Ponderamos na inferência discursiva do qualitativo categorial que a onda retransmissiva via bots para mensagens que viralizam, e ganham mais velocidade de propagação a partir das máquinas, possui poder até $70 \%$ maior de forçar compartilhamentos de mensagens que uma pessoa comum (ID., op. cit.). Então os 3.040 sentidos médios de interpretação para quatro cenários de retransmissão de informações do nosso recorte (a partir das 200 mensagens selecionadas) podem inflacionar exponencialmente para a casa das dezenas de milhares ao assumirmos a variantes intervenientes dos rebatimentos (compartilhamentos por receptores) e da propagação por máquinas. 


\section{Resultados e Discussão}

Exploramos 760 unidades de contexto elementar delimitadas por padrões internos de linguagem e frequência de comunicação. Mediante a coleta de narrativas do chefe do Executivo, significados de palavras e orações foram analisados separadamente e depois agregados para gerar categorias léxico-semânticas. A verossimilhança de agregação das categorias se deu, primeiramente, por um tronco (vertente) comum, a simplicidade das sentenças.

As narrativas presidenciais de avaliação foram classificadas a partir da verificação de conteúdos manifestos e latentes por frequência e padrões que se mostraram muito simplista, do ponto de vista do conteúdo transmitido (Bardin, 2006; Abric, 2005); vejamos os exemplos das afirmações n 43 e n 163 do Presidente da República em Ribeiro (2021):

Se nós nos acovardamos, formos para o discurso fácil, todo mundo em casa, vai ser o caos, ninguém vai produzir mais nada, desemprego tá aí, vai acabar o que tem na geladeira. (Bolsonaro, 25 de março de 2020).

Mesmo que houvesse uma segunda onda [de Covid-19], é só fazer tratamento precoce. Conversa com o médico, tem três medicamentos para outras coisas que servem também para combater a Covid, que a princípio se resolve o assunto. (Bolsonaro, 13 de novembro de 2020)

Em ambas as falas, o Presidente parte de uma avaliação incorreta ou distorcida da situação, para chegar a uma conclusão imprópria e simplista, a saber, uma conclusão que oferece explicações simples, que, porém, ignora fatos e elementos cruciais no raciocínio. Esse padrão se repete em narrativas analisadas no âmbito do léxico e da semântica. Por isso, assumimos como análise primordial primeiramente o viés subjetivo do impacto individual (pessoal) das declarações. Sequencialmente foram explorados rebatimentos coletivos (grupais/sociais) das narrativas e inferências sobre elas a partir de opiniões entre diversos grupos na internet (redes sociais).

Em seguida destacamos o significado real e literal de cada uma das 760 palavras ou orações e equilibramos a interpretação a partir do sentido figurado/metafórico usual delas. A partir daí, dentro da verve simplista observada, cinco categorias foram reunidas a partir de similaridades incidentes. Foram elas:

i) Relativismo (7,5\% ou cerca de 1/13), em que a narrativa presidencial envolveu sentenças em torno de comparações de casos e mortes da covid-19 em função de doenças como zika, AIDS ou mesmo a fome, minimizando a pandemia. ii) Sacralização (12,5\% ou um 1/8), quando falas foram anguladas no sentido de defender a despreocupação ante o vírus porque divindades espirituais e orações curam a doença, independente da precaução, do uso de máscara e do distanciamento social. iii) Desumanização (18\% ou cerca de um 1/5), categoria disseminada pelo chefe do Executivo em torno da dicotomia do valor da economia e do trabalho ante o valor da vida, ameaçando ou culpabilizando prefeitos, governadores e os próprios trabalhadores com discursos sobre a crise financeira do país e a estagnação do trabalho. iv) Negacionismo (30\% ou cerca de um 1/3), que reuniu falas de aspecto político-partidárias, de cunho dogmático, para não aceitar a factibilidade do SARS-CoV-2 ou atribuir a pandemia a teorias conspiratórias. v) Anticiência (32\% ou perto de um 1/3), com narrativas norteadas a partir de curas não científicas, desacreditando a ciência ou desfazendo comprovações atestadas e assentidas pela comunidade científica no tratamento contra o SARS-CoV-2.

O conjunto de categorias auxiliou na tarefa de pensarmos inferências sobre a relação da couvade com a covid-19, questão abordada na sequência. Nesse sentido, relativismo, sacralização, desumanização, negacionismo e anticiência foram bases correlacionais importantes para investigarmos de que maneira agrupamentos populacionais da sociedade se utilizam de padrões comunicacionais baseados nas categorias para acreditar em ou disseminar desinformações e contrainformações, trazendo a termo narrativas do chefe do Executivo como fenômenos de expressividade e reprodutibilidade e ainda assumindo a importância do cargo ocupado pelo Presidente ao proferir as falas. 
Significado e plenipotência de palavras e orações narradas foram comparados por listagem em verbete de dicionário, ordenamento contextual e proximidade representativa entre outras palavras e significados de sintaxe semelhante. Tomemos um exemplo do modelo de Erk (2017) para visualizar a tarefa realizada. A linguista propôs breve exercício, de âmbito comunicativo, para demonstrar a perspectiva, a qual norteou nossas interpretações subjetivas.

Supomos que alguém diga a frase "ele e seus amigos beberam tesbino demais ontem à noite". Ninguém sabe [ou conhece] o que é tesbino [ou se existe de verdade], mas, pelo contexto, dá para saber que é algo que se bebe costumeiramente em grupo e ainda dá para supor que é alcoólico, pois grupos de amigos costumam pedir bebidas alcoólicas à noite. Além disso, se a bebida for alcoólica, sabemos que não se deve beber demais. Então, com apenas uma frase, podemos dizer muita coisa sobre uma palavra completamente desconhecida. Por quê? Porque a palavra tesbino está próxima de outras palavras familiares, com sentidos familiares. Existe um contexto (ID. op. cit.).

Viabilizando o modelo de Erk (2018) para nossa realidade e o problema das fake news abordado, foi aplicado o mesmo princípio de proximidade de sentidos, de viés qualitativo, não para apontar métricas, mas sim pensar categorias que mostrassem o conjunto de reprodutibilidade de crenças agnotológicas sobre a pandemia no Brasil. A sistemática colaborou no comparativo das narrativas tradicionais da couvade com a ordem comunicacional difusa da covid-19 no presente. Para fins de comparação e para ilustrar a complexidade da análise, vejamos a seguinte declaração do Presidente da República em 19 de maio 2020, n 90 em Ribeiro (2021): "Eu acho que quem falou que era veneno, não pode tomar [cloroquina]. Eu sou cristão. O governador pode tomar a cloroquina. Pode ser que não precise. Mas, no seu lugar, eu tomaria (Bolsonaro, 19 de maio de 2020)." Um interpretador dessa narrativa pode não saber bem o que é cloroquina (e naquela altura muitas pessoas com certeza não sabiam), mas pelo contexto pode supor que se trata de um remédio que o Presidente considera eficaz no combate à covid19 (o que, aliás, representa uma postura negacionista em relação à ciência). Além disso, ao efetivamente sugerir que não sejam cristãos, o Presidente implicitamente desqualifica aqueles (os membros da comunidade científica), que consideram a cloroquina (corretamente) ineficaz e potencialmente danosa como tratamento para a covid-19. Dessa forma, a religiosidade da população foi usada para afiançar um remédio ineficaz contra a covid-19. Observamos dessa forma como uma fala pode conter sentidos referentes a diferentes das categorias acima.

\subsection{Crenças agnotológicas simplistas}

O resultado permeou sequências de compreensão para cada uma das 200 sentenças proferidas pelo chefe do Executivo. A análise seguiu a seguinte sistemática. Primeiro escolhemos uma sentença, como a de $\mathrm{n}^{\circ} 31$ (ver abaixo), que foi proferida dia 22 de março de 2020 por Bolsonaro e escalada por nós como comunicação oficial integrante do corpus de análise do estudo. Depois, foram salientados conceitos de proximidade e sentido para a emersão de subjetividades contidas em nível semântico, assim como no que segue na declaração nº 31 do recorte de Ribeiro (2021):

Não podemos nos comparar com a Itália. Lá o número de habitantes por quilômetro quadrado é 200. Na França, 230. No Brasil, 24. O clima é diferente. A população lá é extremamente idosa. Esse clima [de pânico por conta da covid19] não pode vir pra cá porque causa certa agonia e causa um estado de preocupação enorme. Uma pessoa estressada perde imunidade (Bolsonaro, 22 de março de 2020, Brasília, no Palácio da Alvorada).

Sobre a fala em destaque, podemos afirmar que estamos diante de um raciocínio incorreto de ordem pueril e simplista. A narrativa não se sustenta porque desconsidera a vastidão continental do território brasileiro em comparação direta com a Itália, sem ponderar sobre a enorme quantidade de aglomerados subnormais (favelas) e a sabida falta de saneamento básico do Brasil, sem paralelo na Itália (Barbosa, 2020). Ademais, usa uma comparação indevida para defender que "uma agonia e um estado de preocupação enorme" ante o vírus seria descabida e poderia até aumentar a gravidade da pandemia. A fala parece procurar justificar ou ocultar a inércia do Executivo na mitigação da covid-19 (Barberia \& Gómez, 2020), ao relativizar 
indevidamente a gravidade da pandemia e por isso foi incluída entre as 7,5\% sentenças que apontam para esse sentido "relativista".

Assim como descrevemos aqui a avaliação de $\mathrm{n}^{\circ} 31$, fizemos com todo o conjunto de textos das 200 sentenças para distribuirmos as categorias. Foi observado, com isso, que a epidemia de ideias não se resume a uma simples replicação de mensagens ou memes, no sentido de Richard Dawkins (Dawkins, 1989), ipsis litteris, nas redes sociais, como instagram, whatsapp e facebook. A disseminação de fake news ocorre principalmente por meio de mensagens compartilhadas porque quem as recebe faz uma leitura, forma uma representação mental do conteúdo e decide compartilhar, impulsionando diferentes fake news, variantes de uma mesma crença.

E também, como observamos, a crença na existência de um tratamento precoce pode se resumir à crença na eficácia de diferentes remédios (sejam eles cloroquina, ivermectina ou azitromicina). Assim existem diferentes versões de uma mesma crença. A saber: no início da pandemia o "tratamento precoce" incluía com frequência a hidroxicloroquina, o que está mais raro atualmente (D'Amazonas, 2021), preferindo-se focar na ivermectina. Entretanto, mesmo que certa crença tenha chegado a um indivíduo por meio de suporte escrito, a representação mental formada a partir dela pode ter até um caráter mais permanente do que a própria mensagem escrita. Mensagens de redes sociais são tão numerosas que dificilmente podem ser acessadas posteriormente e individualmente para se conferir o teor fidedigno delas, e ainda são armazenadas em telefones que são trocados com frequência por novos aparelhos.

Dessa forma, apesar da ocorrência de uma replicação de mensagens em suporte escrito em redes sociais, existe também uma cadeia paralela de representações mentais e públicas que a acompanha. Por isso, as considerações de Sperber (1996) quanto ao conceito de uma epidemia de ideias se aplicam e, em particular, o "modelo de seleção" descrito em Sperber (1996, capítulo V). Surge então a pergunta: porque essas crenças se propagam com tanta facilidade? Ora, as falas analisadas do Presidente tendem a ser de simples compreensão e em alguns casos propõem supostas soluções simples, mas incorretas, para problemas complexos, o que é algo muito preocupante. Vejamos dois exemplos de falas do chefe do Executivo, ${ }^{\circ} 87$ e $\mathrm{n}^{\circ} 173$ em Ribeiro (2021): "No meu entender, desde o começo, deveria ser o (isolamento) vertical, cuidar das pessoas do grupo de risco e botar o povo pra trabalhar [...]" (13 de maio de 2020) e "O tratamento precoce é o ideal. Sentiu sintoma, vai no médico [...]" (10 de dezembro 2020).

Segundo Sperber (1996) a simplicidade é atributo que facilita a propagação de uma crença, mesma que ela esteja equivocada. Ademais, crenças agnotológicas sobre a pandemia são reflexivas (não têm a sua base nas próprias intuições dos indivíduos, mas são orientadas em outras crenças, por exemplo, na autoridade de outrem sobre o assunto). Assim, como as crenças não podem ser verificadas ou falsificadas por intuições individuais, não ocorrem efeitos cognitivos no sentido de causar contradições com as próprias experiências empíricas. Associada a essa problemática, verificamos que um oitavo $(12,5 \%)$ dos sentidos analisados emergiu apontando a sacralização da questão da pandemia do covid-19, com atribuições de possíveis soluções a forças espirituais com elemento supra-humano incorporado à fala - n 65 em Ribeiro (2021): "[Vou] Pedir um dia de jejum ao povo brasileiro em nome de que o Brasil fique livre desse mal o mais rápido possível" (Bolsonaro, 2 de abril de 2020). Nesse particular, a partir de Sperber, destacamos que crenças religiosas ou crenças de fundo espiritual costumam possuir vertente misteriosa que as torna "viciantes" e concorre fortemente a sua propagação (Sperber, 1996). Ademais, a noção extracorpórea ou espiritual da vida sempre foi, ao longo da história, elemento importante para a reprodutibilidade do que não se consegue explicar ou provar. E no caso desse conjunto de falas de Bolsonaro isso está bastante claro: o chefe do Executivo recorre a esse estratagema discursivo (Erk, 2017) para tonificar sua fala. Chamamos também atenção para crenças que são "políticas" (cf. Sperber, 1996), explicitadas em falas que expressam apoio ou rejeição a uma certa política pública. Vejamos, por exemplo, as declarações do Presidente da República, nº 48 e n 172 em Ribeiro (2021): 
Essa neurose de fechar tudo não está dando certo. Para combater o vírus, estão matando o paciente. Dizem que eu estou mais preocupado com a economia do que com a vida das pessoas. Sem grana tu morre de fome, cara. Morre de depressão, suicídio. Quanto mais desemprego, mais violência (26 de março 2020).

Não adianta começar a fechar tudo de novo. Um lockdown mais rígido acarreta 'mais mortes' (10 de dezembro 2020)

Chamamos atenção ao fato de que crenças que não possuem a priori nenhum fundo político foram também politizadas nas falas do Presidente da República - nº 87, 89 e 156 em Ribeiro (2021):

No meu entender, desde o começo, deveria ser o (isolamento) vertical, cuidar das pessoas do grupo de risco e botar o povo pra trabalhar (...). No Brasil, no meu entender, o movimento errado é se preocupar apenas com a questão do vírus, tem o desemprego do lado. A esquerda tá quietinha. O povo precisa trabalhar (13 de maio de 2020).

Quem é de direita toma cloroquina. Quem é de esquerda toma Tubaína (19 de maio de 2020).

A economia está reagindo, peço a Deus que a gente volte à normalidade e que não inventem a partir do ano que vem, depois das eleições, novos confinamentos, novos lockdowns (5 de novembro de 2020).

Dessa forma, as falas do Presidente situam questões a priori científicas em território político/ideológico. Na última fala, por exemplo, o chefe do Executivo apresenta o lockdown, que é uma amarga necessidade científica, como uma "invenção" política. Salientamos, porém, que não apenas questões científicas são colocadas no campo político/ideológico pelo chefe do Executivo. O suposto fica manifesto na declaração seguinte: "Sobre a vacina, parece que tem coisa esquisita aparecendo, mas não vou falar, para evitar polêmica.” (Ribeiro 2021, Declaração do Presidente da República, n 161 de 12 de novembro de 2020). Nessa fala, o chefe do Executivo dá a entender que, mesmo com preocupações graves relacionadas a vacinas e sendo Presidente da República, seria polêmico se manifestar livremente sobre o assunto (desta maneira, criticando implicitamente a imprensa), e, por extensão, tentar implementar políticas públicas segundo as suas convicções.

Dessa forma, Bolsonaro não está apenas empurrando a ciência para o campo político/ideológico, tentando deslegitimá-la, mas também se contrapondo ao próprio ambiente institucional do país, do qual a imprensa faz parte. Essa atitude é por nós considerada bastante problemática, dada a complexidade do problema abordado, a pandemia, que deveria ser encarado pelo lado científico e não opinativo. Interpretando o cenário conforme sugere Sperber (1996), temos que crenças políticas dependem mais de fatores ecólogicos (ambiente político) do que de fatores intrínsecos (cognitivos) para se reproduzirem.

São crenças que possuem sua base em falas de poder, no discurso de um Presidente, portanto figura de altíssima autoridade, com fácil compreensão e aceitação, o que agiliza sua transmissão e replicabilidade, tendo ainda, em certos casos, apelo de serem reconfortantes e passarem a sensação de que está tudo sob controle, sanando a angústia da incerteza no futuro. E daí que, não havendo mudança no ambiente político, é de se esperar que tais crenças continuariam (como continuaram) gozando de alta reprodutibilidade, gerando controvérsias para toda uma nação.

\subsection{A covid e a couvade}

Foi observado que $62 \%$ dos sentidos que podem ser extraídos das falas analisadas são de cunho negacionista ou anticiência. Na categoria, a insistência em tratamentos sem comprovação científica se repete em diferentes falas, em particular nas que relacionam a cura a um suposto "tratamento precoce", como por exemplo as declarações n ${ }^{\circ} 89$ e 90 do recorte de Ribeiro (2021), reproduzidas acima. Chamamos atenção para o fato que quase $10 \%$ das falas analisadas propagam tratamentos à base de remédios sem eficácia comprovada cientificamente, mas com possíveis efeitos colaterais. A partir da narrativa do Presidente (ou, ao menos, recebendo apoio importante nas suas falas), crenças agnotólogicas em supostos "tratamentos precoces" se difundiram na população. 
Esse tipo de crença na atualidade da pandemia oportunizou a nós traçarmos paralelo entre supostos tratamentos anticientíficos e ineficazes para a covid-19 com uma prática ancestral denominada couvade, que é um costume em diferentes sociedades pré-colombianas de o homem vivenciar simbolicamente o parto de sua mulher e, imediatamente após o nascimento da criança, entrar ele em resguardo de maneira parecida com a própria mãe da criança.

A crença de que a prática é importante para a recuperação da mulher e o desenvolvimento saudável da criança é amplamente difundida, todavia não se sustenta cientificamente. Ou seja, só faz sentido pensarmos que a mulher precisa de um tempo de resguardo para se curar fisicamente da concepção do bebê e não o homem. Mas essa crença se encontra amplamente difundida e, em função disso, Sperber (1996) procura compreender as razões para que esse tratamento histórico, mesmo sem comprovação científica, possa se propagar com tanto sucesso.

De igual modo, nos tempos presentes de pandemia, trouxemos essa perspectiva de investigação sperberiana, alocando-a para crenças não-científicas, como a do uso de hidroxicloroquina/cloroquina ou de outros tratamentos farmacológicos precoces, males genéticos da vacina contra o SARS-CoV-2 (ou suas variantes) e outras crenças antifáticas. Verificamos como elas têm se reproduzido de maneira acelerada e assustadora, com alto teor de aceitabilidade entre a população, mesmo diante da comprovação da ciência de que são ineficazes.

Assim, buscamos traçar semelhanças entre a crença na importância da couvade e algumas crenças referentes à pandemia. Desta feita, a partir daqui, portanto, focamos a análise nas crenças relativizando a pandemia e nas crenças negacionistas (rechaçando a pandemia) e anticientíficas (negando a eficácia do uso de máscaras, do distanciamento social, da vacinação, e acreditando na eficácia de remédios como hidroxicloroquina e outros do assim chamado "kit covid").

Para começar essa parte final da análise, notemos:

1) As crenças na utilidade da couvade e as crenças referentes à covid-19 mencionadas acima são todas reflexivas e não intuitivas (no sentido de Sperber), pois são crenças baseadas em uma outra segunda crença. Por exemplo, a crença na eficácia da couvade pode ser enxergada como a combinação de duas crenças: "os anciões dizem a verdade" e "os anciões dizem que a couvade é eficaz". De forma semelhante há pessoas, influenciadores sociais ou políticos, que são tidos como confiáveis e fazem afirmações factualmente incorretas a respeito da covid-19.

2) Todas estas crenças não possuem base fática ou científica. Inclusive, agir em função dessas crenças faz mais mal do que bem (a couvade priva o pai do recém-nascido de nutrientes durante vários dias e remédios sem eficácia para a covid-19 não deixam possuir efeitos colaterais). Dessa maneira, Sperber aponta que a prática da couvade não pode ser facilmente explicada de forma funcionalista. Mas, pelo contrário, é relativamente fácil tecer um argumento do ponto de vista funcional que a couvade já deveria ter desaparecido através das gerações. De forma semelhante, é possível argumentar (do ponto de vista funcional) que as crenças sobre a covid-19 elencadas acima, como, por exemplo, o uso de hidroxicloroquina para prevenir ou tratar a doença, deveriam já ter desaparecido, pois só aumentam o risco de mortalidade e não o diminuem.

3) Todas essas crenças são simples de se expressar. As seguintes falas, por exemplo, expressam e reforçam a crença de que vacinas não sejam seguras e possam ser até altamente perigosas - declarações nº 159 e 180 em Ribeiro (2021):

Morte, invalidez, anomalia. Esta é a vacina que o Doria queria obrigar a todos os paulistanos tomá-la. O presidente disse que a vacina jamais poderia ser obrigatória. Mais uma que Jair Bolsonaro ganha (11 de novembro de 2020).

Lá no meio dessa bula está escrito que a empresa não se responsabiliza por qualquer efeito colateral. Isso acende uma luz amarela. A gente começa a perguntar para o povo: você vai tomar essa vacina? (16 de dezembro 2020)

Ademais, as falas $n^{\circ} 48,89,90,156,163$ e 173 do recorte de Ribeiro (2021), acima reproduzidas, expressam crenças na existência de remédios eficazes na prevenção da covid-19 ou assumem como verdade a ineficácia de medidas de 
distanciamento social. Nesse sentido, chamamos também atenção para as falas relacionadas à inutilidade de máscaras, vejamos a declaração nº 193 (Ribeiro 2021):

Falam tanto em máscara. O tempo todo essa mídia pobre falando: "o presidente sem máscara". Não encheu o saco ainda, não? - afirmou o presidente. - Isso é uma ficção. Quando é que nós vamos ter gente com coragem, que eu não sou especialista no assunto, para falar que a proteção da máscara é um percentual pequeno? A máscara funciona para o médico, que está operando. Uma máscara específica. A nossa aqui, praticamente zero. (31 de dezembro de 2020).

Do ponto de vista cognitivo, segundo Sperber, o simplismo das mensagens contidas em todas essas falas é um atributo fortalecedor a elas, que facilita propagação e continuidade a médio e longo prazo. O teor simplista está longe de ser relacionado à objetividade do narrador ou sua boa comunicação. Pelo contrário. Os sentidos do reducionismo e do falseamento se sobressaem, concorrendo para a cadeia viciosa das fake news.

Além de semelhanças entre crenças da eficácia da couvade e tratamentos anticientíficos para a covid-19, podemos analisar as crenças agnotológicas sobre a pandemia de um ponto de vista cognitivo individual - à semelhança da análise da couvade em Sperber (1996, capítulo II). Podemos distinguir quatro casos possíveis:

a) O indivíduo age estritamente em função da sua crença, e não acontece nenhum infortúnio.

b) O indivíduo age estritamente em função da sua crença, e acontece um infortúnio.

c) O indivíduo não age estritamente em função da sua crença, e não acontece nenhum infortúnio.

d) O indivíduo não age estritamente em função da sua crença, e acontece um infortúnio.

Segundo Sperber, com o passar do tempo, uma análise desses quatro casos deveria mostrar para os indivíduos envolvidos que a prática da couvade não reduz realmente a probabilidade da ocorrência de um infortúnio (o adoecimento do recém-nascido, por exemplo) e que deixar de praticar a couvade corretamente também não aumenta a chance de uma enfermidade do recém-nascido. Em razão isso a prática da couvade deveria ser abandonada com o passar dos anos. Entretanto, uma tal "erosão cognitiva" da couvade não ocorreu. Logo, concluímos que os indivíduos que praticam a couvade permanecem indiferentes a fatos observados ou fazem inferências inadequadas. Como Sperber aponta, em avaliação transversal, humanos e alguns outros animais possuem capacidade de avaliar probabilidades, porém essas mesmas são muitas vezes mal compreendidas - como de fato ocorre no caso da couvade. Essas considerações se aplicam também às crenças agnotológicas sobre a covid-19 nos.

Objetivamente, inferências incorretas sobre probabilidade são abundantes nas falas do próprio presidente. Vejamos as declarações n 116 e 195 (Ribeiro 2021):

É um testemunho meu. [A hidroxicloroquina] Deu certo e estou muito bem. Aqueles que criticam, apresentem uma alternativa (9 de julho de 2020).

Não tem de ter medo da hidroxicloroquina. Ela não causa arritmia. Não faz mal a hidroxicloroquina. Comigo deu certo. Não fique no lero-lero. Eu tomei imediatamente a hidroxicloroquina. O tratamento precoce é a solução e a chave dessa questão $\left(1^{\circ}\right.$ de janeiro de 2021$)$.

Em ambas as falas, o Presidente não só alega nexo causal entre seu uso da hidroxicloroquina e sua cura, como também considera a sua cura argumento suficiente para tentar convencer outras pessoas que ele encontrou "a solução e a chave" da pandemia da covid-19. Na primeira das falas, inclusive, apontamos também para o uso da palavra "testemunho", que mobiliza a prática de relatar supostas curas como sendo fidedignas (comum em cultos evangélicos), assim acrescentando uma dimensão de sacralização a uma questão de fundo puramente científico. 
Ademais, foi possível observar empiricamente por um dos autores do presente trabalho conversas de whatsapp sobre supostos tratamentos à base de remédios ineficazes contra a covid-19. Essas conversas apontaram para a avaliação equivocada de probabilidades e inferências inadequadas por parte de indivíduos, espelhando exatamente esse tipo raciocínio falho do Presidente da República. O episódio deu-se da seguinte forma. Um dos autores desse trabalho afirmou em grupo de whatsapp que "não existe tratamento precoce", comentando uma postagem de outro membro. Com isso, surgiu a seguinte conversa:

Membro A: "Todas as pessoas da minha família que tiveram covid-19 tomaram esses remédios e não tiveram nenhum sintoma grave." [...]

Membro A: "Cada um faz o que bem entender, Graças a Deus e a esses remédios não perdi nenhum familiar." [...]

Membro B: "Sim man [sic], eu também minha avó de 62 anos fez uma consulta com um médico ele disse que não podia fazer nada uma semana depois fizemos outra consulta com outro médico e passoi [sic] alguns medicamentos, e ela tomou tudo e está bem graças a Deus" [...]

Em seguida a essas afirmações, o autor deste estudo rebateu que "as evidências científicas são muito claras que isso [a cura] não é devido a nenhum dos remédios do suposto "tratamento precoce"” e que os familiares mencionados "provavelmente tiveram sorte". Em contraposição a essa afirmativa, foi observada certa repulsa entre os membros do grupo. Em seguida a um clima de tensão entre os integrantes, outro membro do grupo (membro C) destacou de forma irônica: "Membro C: 'Se o remédio fizer o bem vamos pôr na conta da sorte. Muito boa. Legal mesmo' [...]”

Em suma, analisando esse diálogo, observamos que o membro A atribuiu claramente a baixa gravidade de manifestação da doença a medicamentos do assim chamado "tratamento precoce". Claro que é impossível saber se os familiares referidos pelo membro do grupo de fato tomaram esses remédios, mas o que importa é que o membro A esteve disposto a fazer essa inferência, negligenciando obviamente o fato de que o número de casos leves de covid-19 é muito maior do que o de casos graves, o que mostra muito bem o que destacamos como dificuldade de avaliar probabilidades, e sobre esse particular salientamos também a fala do membro C.

Sobre as afirmaç̃oes do membro B, elas não se referem necessariamente a medicamentos do "kit covid", mencionados acima. Porém, de todos os modos, essa pessoa se dispôs a fazer uma referência inadequada e equivocada, afirmando que a cura de sua avó, devido a medicamentos prescritos, seria uma evidência da eficácia dos remédios prescritos a partir do "tratamento precoce".

De modo global, avaliando os entremeios desse exemplo de comunicação e trazendo à baila as colocações de Sperber (1996), seria difícil a esses indivíduos do grupo de whatsapp fazerem afirmações inadequadas, em tom de juízo de valor, caso as experiências deles próprios apontassem claramente que a reprodução desses tipos crenças é altamente perigosa e teria grande potencial de gerar infortúnios. Porém, a taxa de fatalidade por infecção é relativamente baixa da covid-19 e o teor nocivo do remédio não indicado para a covid-19 também é relativamente limitado, para que uma tal "erosão cognitiva" das crenças ocorra.

E da mesma forma como ocorreu nesse grupo de whatsapp na pandemia, Sperber (1996) aponta que, ancestralmente, a prática da couvade de igual modo não tem potencial nocivo suficiente para que ela possa deixar de se replicar em razão disso. Surgem assim, então, as seguintes perguntas: Se a covid-19 fosse uma doença mais grave ou mais letal, essas crenças agnotológicas poderiam deixar de se replicar, sofrendo uma "erosão cognitiva"? Dentro do atual ambiente político e (potencialmente no futuro) fora dele, dadas as características biológicas do vírus SARS-CoV-2 e de suas variantes, quais são as probabilidades da replicação continuada dessas crenças agnotológicas?

Argumentamos que não há critérios cognitivos que possam fazer as pessoas abandonarem essas crenças prejudiciais a elas, dadas as características (atuais) da covid-19. Todavia, talvez seja digno avaliarmos as diferenças importantes entre a crença na eficácia da couvade e da reprodução de fake news anticientíficas. Vamos a elas: 
a) As origens da couvade não são conhecidas, porém é possível identificar que essa crença se baseia na confiança que membros de sociedades possuem em seus anciões (aînés). Assim, o processo de transmissão da crença embasa-se em explicações ancoradas em parentesco e herança clânica, ambos de viés metafísico e totêmico. Por sua vez, crenças agnotológicas sobre a covid-19 são propagadas por razões e forças políticas, tendo origens conhecidas (pelo menos na forma em que elas se encontram difundidas atualmente) em movimentos políticos. Fatores ecológicos, no caso o ambiente político, possuem então importância na propagação.

b) Crenças sobre a covid-19 se propagam em uma cultura com letramento e meios de disseminação de informação eficientes. Dessa forma, crenças sobre a covid-19 se transmitem por cadeias causais de boates e rumores, com suporte em redes sociais (análogo a uma epidemia biológica de transmissão horizontal), diferente da crença na eficácia da couvade, transmitida lentamente de geração em geração (comparável a uma endemia biológica de transmissão vertical). A replicação de mensagens por whatsapp também (sem o risco de modificações a cada transmissão, que podem facilmente ocorrer em culturas orais) possibilita uma análise por perspectiva da evolução darwiniana (em que sobrevivem as mais impactantes mensagens), enxergando as mensagens de whatsapp como memes no sentido de Dawkins (1989). Sendo propagadas por whatsapp há uma replicação fiel das ideias em função da facilidade e da rapidez para a disseminação. Todavia, argumentamos que tal análise não descreveria adequadamente a epidemia de ideias que ocorre paralelamente à disseminação das fake news pelo suporte físico.

c) As escalas temporais são diferentes. A couvade se propaga lentamente através das gerações e as crenças sobre a covid-19 em paralelo a uma epidemia biológica em uma escala de meses ou poucos anos. Conforme Sperber (1996), a couvade seria análoga a uma endemia e as crenças agnotológicas sobre a covid-19 a uma epidemia.

\section{Conclusão}

Concluímos que existe uma epidemia de fake news e de crenças agnotológicas ocorrendo em paralelo à pandemia biológica, crenças estas que são propagadas e encontram suporte em falas do Presidente da República. Chamou nossa atenção que quase dois terços dos sentidos que podem ser extraídos dessas falas são de cunho anticientífico e negacionista. Uma análise aprofundada permite concluir que as principais crenças agnotológicas expressas na conjuntura das narrativas difundidas amplamente na população possuem atributos que podem fazer com que elas continuem se propagando, a não ser que haja uma mudança importante no ambiente ecológico (político), dando a oportunidade para que as categorias de narrativas mudem.

Esses atributos incluem certo simplismo de suas ideias principais, uma tendência ao apelo a forças sobrenaturais (sacralização) e uma politização de questões científicas e até institucionais do país. Tanto que nos foi possível traçar um paralelo dessas crenças agnotológicas (em particular, sobre supostos "tratamentos precoces") sobre a covid-19 com a crença na eficácia da prática da couvade, comum em diferentes civilizações pré-colombianas: de fato, não é fácil explicar tais crenças do ponto de vista funcional, aliás, agir a em função dessas crenças pode até ser nocivo. Todavia, potenciais malefícios não ocorrem com frequência suficiente para provocar uma "erosão cognitiva" dessas crenças, isto é, a covid-19, por exemplo, não apresenta uma taxa de casos graves tão alta que o indivíduo acabe se convencendo por suas próprias experiências (ou aquelas de pessoas próximas) que um certo "suposto" tratamento de fato não é eficaz. Pelo contrário, a taxa de letalidade é suficientemente "baixa" para que o uso de certos remédios sem eficácia real produza um grande número de "testemunhos" de cura que são atribuídas àqueles remédios - a imagem da fala do Presidente n 116 , acima (Ribeiro, 2021). 
Nos tempos recentes, observou-se um crescimento na difusão de crenças agnotológicas sobre as vacinas contra covid19 (Gullino, 2022). Acreditamos que a nossa análise sperberiana pode ser aplicada em trabalhos futuros a estas crenças também. Além disso seria interessante analisar o efeito da CPI do Senado sobre a pandemia da covid-19 (Senado Federal, 2021) no ambiente ecológico (político) e, em consequência, na disseminação das crenças agnotológicas que está em curso no país. De forma mais geral, seria interessante acompanhar a dinâmica da difusão de crenças agnotólogicas sobre a pandemia da covid-19 a longo prazo, a fim de verificar a nossa hipótese que uma "erosão cognitiva" dessas crenças é improvável, assim como para analisar os efeitos de mudanças no ambiente ecológico (político) na difusão dessas crenças. Ressaltamos que muitas das descobertas científicas recentes não são facilmente verificadas a nível individual. Por exemplo, não é realmente possível se convencer da eficácia das vacinas contra a covid-19 ao observar apenas a sua própria experiência com a vacinação ou nãovacinação. Apenas analisando dados sobre a vacinação, casos de covid-19, internações e óbitos de uma população grande é possível verificar a eficácia das vacinas disponíveis para prevenir casos graves de covid-19 (Scobie, 2021). Dessa forma, o ato de abandonar uma crença agnotólogica depende mais, por exemplo, da disposição em aceitar dados oficiais sobre a pandemia (algo que tende a ser influenciado pelo ambiente político) do que de uma análise cuidadosa da própria experiência individual durante a pandemia (que poderia servir de base para uma possível "erosão cognitiva").

Por fim, a nossa pesquisa aponta claramente para o fato de que no Brasil estamos diante uma epidemia de ideias sperberiana, manifestada a partir de uma dialética psicossocial envolvendo três fatores, negação, conformação e aceitação, dentro de uma antropologia da morte (Engelke, 2019). Esses fatores tendem a concorrer para a política estatal de produção de ignorância em plena pandemia. Essa antropologia da morte dá sinais de que está sendo incentivada pelo chefe do Executivo e inúmeros de seus seguidores, seja em boa parte de suas atitudes ou em suas falas, como enfocamos neste artigo.

\section{Agradecimentos}

Os autores gostariam de agradecer aos revisores pela leitura detalhada e os comentários pertinentes que melhoraram o manuscrito. Os autores foram parcialmente apoiados pela Coordenação de Aperfeiçoamento de Pessoal de Nível Superior (CAPES).

\section{Referências}

Abric, J. C. (2005). A zona muda das representações sociais. In: D. C. Oliveira \& P. H. F. Campos (Orgs.). Representações sociais, uma teoria sem fronteiras. (pp. 23-34). Rio de Janeiro: Ed. Museu da República, 2005.

Ajzenman, N. Cavalcanti, T. \& da Mata, D. (2020). More Than Words: Leaders' Speech and Risky Behavior during a Pandemic. SSRN. https://doi.org/10.2139/ssrn.3582908

Albuquerque, R.; Leão, J.; Steinmetz, W. A., \&Orellana, J. (2020). Os desaparecidos da covid-19. Quarentenas Amazônicas, 6. Alex Cultural: Embu das Artes/SP. EDUA.

Amazonas Atual. (2021). Taxa de mortalidade por Covid-19 no Amazonas ainda é a mais alta do país. AM/Atual. https://amazonasatual.com.br/taxa-demortalidade-por-covid-19-no-amazonas-ainda-e-a-mais-alta-do-pais/

Andrade, R. (2020). Covid-19 is causing the collapse of Brazil's national health service. BMJ, 370, m3032, 2020. https://doi.org/10.1136/bmj.m3032

Aos Fatos, (2021). Fact-checking journalism agency. Site Aos Fatos. https://www.aosfatos.org/todas-as-declara\%C3\%A7\%C3\%B5es-de-bolsonaro/

Associação Médica Brasileira (AMB). 2021. Os médicos e a pandemia de Covid-19. https://amb.org.br/wp-content/uploads/2021/02/PesquisaAPM_AMB_FGV_m\%C3\%A9dicos-e-covid-19_fev2021.pdf

Barberia, L. \& Gómez, E. (2020). Political and institutional perils of Brazil's COVID-19 crisis. The Lancet. 2020 8-14 August; 396(10248): 367-368. https://doi.org/10.1016/S0140-6736(20)31681-0

Barbosa, L. (2020). As favelas que a pandemia criou. Outras Mídias - Projeto Solos. https://outraspalavras.net/outrasmidias/as-favelas-que-a-pandemia-criou/ Bardin, L. (2006). Análise de conteúdo - L. de A. Rego \& A. Edições 70. (Obra original publicada em 1977). 
Barrucho, L. (2021). 'Manaus virou capital mundial da covid-19 e lockdown é única alternativa', diz pesquisador. BBC News Brasil/Londres. https://www.bbc.com/portuguese/brasil-55681527

Candido, D. S. et al. (2020). Evolution and epidemic spread of SARS-CoV-2 in Brazil. Science, eabd2161, 2020. https://doi.org/10.1126/science.abd2161

Canzian, F. (2020). Falas de Bolsonaro contra isolamento podem ter matado mais seus eleitores, aponta estudo. Folha de São Paulo. In https://www1.folha.uol.com.br/equilibrioesaude/2020/06/falas-de-bolsonaro-contra-isolamento-podem-ter-matado-mais-seus-eleitores-aponta-estudo.shtml

Cesarino, L. (2019). On Digital Populism in Brazil. PoLAR: Political and Legal Anthropology Review, 3-5, 2019.

D’Amazonas, A. (2021). https://www.instagram.com/tv/CKCovbEjKaP/. 2021

Dawkins, R. (1989). The Selfish Gene (2 ${ }^{\text {nd }}$ ed.), Oxford. Oxford University Press.

Engelke, M. (2019). The Anthropology of Death Revisited. Annual Review Of Anthropology, 48(1), 29-44, Annual Reviews. http://doi.org/10.1146/annurevanthro102218-011420.

Erk, K. (2010). What is word meaning, really? (and how can distributional models help us describe it?). Proceedings of the Workshop on Goometrical Models of Natural Language Semantics, 17- 26. Uppsala, Sweden: Association for Computational Linguistics.

Erk, K. (2009). Representing words as regions in vector space. Proceedings of CoNLL, Boulder, CO: Association for Computational Linguistics.

Erk, K. (2017). Sim, há uma distância entre as palavras. Imaginário Puro. Entrevista a Márcio Simões. In: https://imaginariopuro.wordpress.com/2017/03/17/sim-ha-uma-distancia-entre-as-palavras/

Estadão. (2021, 25 de março). https://www.istoedinheiro.com.br/cfm-nega-rever-aval-a-prescricao-de-cloroquina/

Ferrante, L., Steinmetz, W. A., Almeida, A. C. L., Leão, J., Vassão, R. C., Tupinambás, U., Fearnside, P. M., Duczmal, L. H. (2020). Brazil's policies condemn Amazonia to a second wave of COVID-19. Nature Medicine, 26, 1315 (2020). https://doi.org/10.1038/s41591-020-1026-x

Graves, L. \& Amazeen, M. (2019). Fact-Checking as Idea and Practice in Journalism. Oxford Research Encyclopedia of Communication. https://doi.org/10.1093/acrefore/9780190228613.013.808

Greifender, R., Jaffé, M. E., Newman, E. J. \& Schwarz, N. (Eds.) (2021). The Psychology of Fake News: Accepting, Sharing, and Correcting Misinformation. Routledge (Taylor \& Francis).

Gullino, D. (2022, 06 de janeiro). Bolsonaro critica liberação de vacinas para crianças: 'Qual o interesse das pessoas taradas por vacina?'. $O$ Globo. https://oglobo.globo.com/saude/bolsonaro-critica-liberacao-de-vacinas-para-criancas-qual-interesse-das-pessoas-taradas-por-vacina-1-25343618

Hallal, P. (2021). SOS Brazil: science under attack. Correspondence. The Lancet. 397(10272), P373-374. https://doi.org/10.1016/S0140-6736(21)00141-0

Iamarino, A. (2021). O que acontece em Manaus? Com a demógrafa Márcia Castro. YouTube. https://www.youtube.com/watch?v=oOcITdkLKkk\&t=2738s

Lowy Institute. (2021). Covid Performance Index - Deconstructing Pandemic Responses. https://interactives.lowyinstitute.org/features/covid-performance/

Mauss, M. (1974). Ensaio sobre a dádiva, forma e razão da troca nas sociedades arcaicas. In: Lévi-Strauss, C. Sociologia e antropologia. 2. EPU/EDUSP.

Moscovici, S. (2003). Representações sociais: investigações em psicologia social. Rio de Janeiro, Vozes. 404 páginas (trad. Pedrinho A. Guareschi, a partir da língua inglesa - Social representations: explorations in social psychology [Gerard Duveen, Polity Press/BlackwellPublishers, 2000]).

OPAS (Organização Panamericana de Saúde). 2020. OPAS descreve melhores práticas para controlar pandemia de COVID-19. PAHO. In https://www.paho.org/pt/noticias/11-11-2020-opas-descreve-melhores-praticas-para-controlar-pandemia-covid-19

Preite Sobrinho, W. (2021, 13 de janeiro). "Sabotador", Bolsonaro foi parado pelas instituições, diz Human Rights. UOL. In https://noticias.uol.com.br/politica/ultimas-noticias/2021/01/13/bolsonaro-human-rights-watch-relatorio-covid-19-brasil.htm

Recuero, R., Soares, F. \& Zago, G. (2021). Polarização, Hiperpartidarismo e Câmaras de Eco: Como circula desinformação sobre a Covid-19 no Twitter. Contracampo, 40(1). https://doi.org/10.1590/SciELOPreprints.1154

Ribeiro, M. (2021). Brasil, 200 mil mortes por Covid: 200 frases de Bolsonaro minimizando a pandemia. Yahoo! Notícias. https://esportes.yahoo.com/noticias/200-frases-de-bolsonaro-minimizando-a-pandemia-do-coronavirus-203647435.html

Rosenfeld, A. \& Erk, K. (2018). Deep Neural Models of Semantic Shift. Proceedings of Proceedings of Association for Computational Linguistics. New Orleans, Louisiana, Jun 1-6, 474-484, 2018. In https://www.aclweb.org/anthology/N18-1044.pdf

Ruediger, M. A. \& Grassi, A. (2020). Desinformação on-line e processos políticos: a circulação de links sobre desconfiança no sistema eleitoral brasileiro no Facebook e no YouTube (2014-2020). Policy paper. Rio de Janeiro: FGV DAPGV-DAPP. (2020). http://bibliotecadigital.fgv.br/dspace/handle/10438/30085

Satie, A. (2020). Datafolha: $22 \%$ dos brasileiros não pretende se vacinar contra Covid-19. CNN Brasil. https://www.cnnbrasil.com.br/saude/2020/12/12/datafolha-22-dos-brasileiros-nao-pretendem-se-vacinar-contra-covid-19

Schelp, D. (2020). Cúpula bolsonarista faz 30\% dos tuítes que promovem teoria conspiratória. UOL Colunas. https://noticias.uol.com.br/colunas/diogoschelp/2021/02/04/cupula-bolsonarista-faz-30-dos-tuites-que-promovem-teoria-conspiratoria.htm

Scobie, H. et al. (2021). Monitoring Incidence of COVID-19 Cases, Hospitalizations, and Deaths, by Vaccination Status - 13 U.S. Jurisdictions, April 4-July 17, 2021. Center for Disease Control and Prevention. https://www.cdc.gov/mmwr/volumes/70/wr/mm7037e1.htm 
Research, Society and Development, v. 11, n. 2, e10311225349, 2022

(CC BY 4.0) | ISSN 2525-3409 | DOI: http://dx.doi.org/10.33448/rsd-v11i2.25349

Senado Federal. (2021). CPI da Pandemia. https://legis.senado.leg.br/comissoes/comissao?codcol=2441

Sperber, D. (1996). La Contagion des idées. Versão francesa. Editions Odile Jacob.

Sperber, D. (1985). Anthropology and psychology: towards an epidemiology of representations (The Malinowski Memorial Lecture 1984). Man, 20, 73-89, 1985.

Sperber, D. \& Wilson, D. (1986/1995). Relevance: communication and cognition. Blackwell, Cambridge.

SBIM (Sociedade Brasileira de Imunizações). 2021. Mitos e verdades sobre as vacinas COVID-19, https://familia.sbim.org.br/duvidas/mitos/mitos-everdades-sobre-as-vacinas-covid-19

Sousa Júnior, W. C. de, Gonçalves, D. A. \& Cruz, D. B. (2020). COVID-19: Local/regional inequalities and impacts over critical healthcare infrastructure in Brazil. Ambiente \& Sociedade, 23, e0114. https://doi.org/10.1590/1809-4422asoc20200114vu202013id

Tarde, G. de. (1890). Les lois d'imitation. Éditeur Félix Alcan.

Teixeira, M. (2021). Inquérito das fake news avança em suspeitas contra chapa de Bolsonaro, mas TSE não tem pressa. Folha de São Paulo. https://www1.folha.uol.com.br/poder/2021/03/inquerito-das-fake-news-avanca-em-suspeitas-contra-chapa-de-bolsonaro-mas-tse-nao-tem-pressa.shtml

The Lancet [Editorial]. COVID-19 in Brazil: “So what?”. The Lancet, 395(10235), P1461. https://doi.org/10.1016/S0140-6736(20)31095-3.

Travassos, L., Moreira, R., \& Cortez, R. S. (2020). The virus, the disease and the inequality. Ambiente \& Sociedade, 23, e0111. https://doi.org/10.1590/18094422asoc20200111vu202013id.

Vala, J. (2003) A Análise de Conteúdo. In: A. S. Silva; J. M. Pinto (Orgs.). Metodologia das Ciências Sociais. (12a ed.), Edições Afrontamento 101-128.

Veiga e Silva, L. et al. (2020). COVID-19 Mortality Underreporting in Brazil: Analysis of Data From Government Internet Portals. Journal of Medical Internet Research, 22(8), e21413. https://doi.org/10.2196/21413

Vosoughi, S., Roy, D. \& Aral, S. (2018). The spread of true and false news online. Science. 359(6380), 1146-1151. https://doi.org/10.1126/ science.aap9559

Taylor, L. (2020). How Latin America is fighting covid-19, for better and worse. BMJ, m3319. http://doi.org/10.1136/bmj.m3319.

Zattar, M. (2017). Competência em informação e desinformação: critérios de avaliação do conteúdo das fontes de informação. Liinc em Revista, 13(2), 285293. https://doi.org/10.18617/liinc.v13i2.4075 